\title{
Postpubertal gluten challenge in coeliac disease
}

\author{
M MÄKI, ${ }^{*}$ M-L LÄHDEAHO, ${ }^{*}$ O HÄLLSTRÖM, $\dagger$ M VIANDER, $\ddagger$ AND J K VISAKORPI* \\ Departments of ${ }^{*}$ Paediatrics and †Microbiology, University Hospital of Tampere, Tampere and $\ddagger$ Department \\ of Medical Microbiology, University of Turku, Turku, Finland
}

SUMMARY Altogether 38 postpubertal children with coeliac disease were rebiopsied. Mucosal abnormality in nine $(24 \%)$ of them indicated poor adherence to the diet. Gluten challenge with a diet containing a normal amount of gluten was performed in those 29 patients with a normal mucosa. During challenge, rebiopsy was done when reticulin antibodies turned positive (mean 0.6 years, range $0.2-2 \cdot 0$ ) or at the end of the two year study. Histologically a clear relapse into coeliac disease was seen in all 23 patients who were positive for reticulin antibodies. At this time gliadin antibodies were positive in all but two. Sixteen $(70 \%)$ of those who relapsed were completely asymptomatic. Three girls and one boy did not relapse within two years, indicating the possible recovery from coeliac disease to be $11 \%$. All four had undergone gluten challenge earlier in childhood, after initial diagnosis and mucosal recovery, and this had resulted in mucosal relapse. To establish definite postpubertal recovery from coeliac disease in cases with normal mucosa at two years from challenge, further follow up studies of reticulin antibodies and later rebiopsy are needed. The reticulin antibody test seems to be suitable for prediction of mucosal relapse in coeliac disease.

The European Society for Paediatric Gastroenterology and Nutrition (ESPGAN) criteria for diagnosing coeliac disease include, after initial diagnosis, prechallenge verification of normal small bowel mucosa and postchallenge mucosal relapse. ${ }^{12}$ In Finland the clinical picture of coeliac disease has changed to milder forms, resulting in an upward shift of age at diagnosis. ${ }^{3}$ In fact, over $60 \%$ of the diagnoses today are made at school age and during adolescence. The current problem is when to apply gluten challenge in children with late diagnosis. It has also been discussed whether routine gluten challenge should be performed at all, as only a few patients with coeliac disease will not relapse after gluten reintroduction. ${ }^{4}$ On the other hand puberty could be a milestone in coeliac disease, after which the disease behaves differently. In fact, Schmitz et al have shown spontaneous remissions of coeliac disease during adolescence. ${ }^{5}$ Therefore we felt it appropriate to reinvestigate children with coeliac disease postpubertally.

We have now performed postpubertal gluten challenge on adolescents and young adults in whom the diagnosis of coeliac disease was made both in infancy, including gluten challenge, and at a later age. The purpose of the study was to establish whether there are patients with coeliac disease already fulfilling the ESPGAN criteria and probable patients who do not relapse postpubertally within two years on a diet containing gluten. We also hypothesised that only one biopsy would be needed during gluten challenge, the appearance of reticulin antibodies during the challenge being the indicator for rebiopsy. At the same time gliadin antibodies were also measured.

\section{Patients and methods}

\section{STUDY DESIGN}

Altogether 42 adolescents and young adults were asked to join the study. They were informed as to the study programme, which included initial biopsy and gluten challenge by means of a diet containing a normal amount of gluten but with at least $10 \mathrm{~g}$ of gluten per day. Follow up visits were to be made first after one month and later every three months during the challenge or in the meantime if symptoms occurred. Blood samples for IgA and IgG class reticulin and gliadin antibodies were to be drawn at the follow up visits. The study also included rebiopsy at the time of appearance of reticulin antibodies or symptoms, with a deadline of two years of gluten challenge. The patients were told that they would most probably have to return to the gluten 
free diet after the study, but also that coeliac disease might disappear during adolescence as suggested by Schmitz et al. ${ }^{5}$

\section{PATIENTS}

A total of four patients refused to join the study and continued with a gluten free diet. Thirty eight patients underwent initial small bowel biopsy and nine $(24 \%)$ of them were excluded from the study because of apparent poor adherence to the diet and the finding of mucosal changes compatible with coeliac disease (from slight partial villous atrophy to flat mucosa).

A diet containing a normal amount of gluten was reintroduced in 29 patients (13 boys and 16 girls). All had normal small bowel mucosa on biopsy and all were negative for reticulin antibodies. Mean age at commencement of the study was 16.6 years (range 14-3-22-1). ESPGAN criteria with an earlier gluten challenge had been fulfilled in 20 patients. The median age of these 20 patients at the initial diagnosis was 1.0 year (range $0 \cdot 5-4 \cdot 0$ ). They had been on a gluten free diet before this second challenge for a mean of $8 \cdot 5$ years (range 3.0-13.0). The median age at the initial diagnosis of the nine patients undergoing their first gluten challenge was $10 \cdot 0$ years (range $1 \cdot 0-15 \cdot 3$ ). The mean duration of gluten free diet was $7 \cdot 8$ years (range $4 \cdot 0-16 \cdot 0$ ).

\section{METHODS}

Reticulin antibodies were measured by an indirect immunofluorescence method with some modifications $^{67}$ to the preliminary report. ${ }^{8}$ Serum titres equal to or over 1:50 were considered positive. An enzyme linked immunosorbent (ELISA) method was used to determine the titre of gliadin antibodies in the sera. ${ }^{9} 10$

Routine small bowel biopsy was performed with an adult Watson capsule. Histologically the mucosal findings were divided into four groups: normal, partial villous atrophy, severe partial villous atrophy, and subtotal villous atrophy or flat mucosa.

\section{Results}

Twenty two patients who were negative for $\operatorname{IgA}$ class reticulin antibodies became positive within $0 \cdot 2-2 \cdot 0$ years (mean $0 \cdot 6$ ). The titres varied from $1: 100$ to $1: 4000$. Fifteen of the 22 adolescents and young adults had noticed no changes in their well being and seven had experienced slight to moderate abdominal symptoms at the time of appearance of reticulin antibodies. One patient had selective $\operatorname{IgA}$ deficiency: she had no $\operatorname{Ig} \mathrm{A}$ reticulin antibodies throughout but after 0.9 years of gluten challenge she was found to be positive for IgG class reticulin antibodies (1:200). No symptoms had occurred.

In all 23 patients who were positive for reticulin antibodies a clear mucosal relapse was observed on biopsy. Seventeen patients $(74 \%)$ showed small, flat intestinal mucosa, two patients showed severe partial villous atrophy, and four moderate partial villous atrophy.

One patient developed intolerable abdominal symptoms after 0.4 years on gluten challenge. She had no reticulin antibodies and the gliadin antibodies showed a slight positivity but the small bowel mucosa was normal. Despite subjective symptoms she continued the challenge and a second biopsy was performed because of the symptoms after 0.8 years on gluten challenge and the biopsy specimen showed slight partial villous atrophy. She still had no reticulin antibodies. She returned to a gluten free diet.

After two years on a gluten containing diet five patients were still negative for reticulin binding antibodies and had no symptoms. They all had a small bowel biopsy. One patient showed a flat mucosa and on retesting his serum the $\operatorname{IgA}$ class reticulin antibodies gave a titre of $1: 10$. Three girls and one boy did not relapse, and the mucosa was found to be normal. Thus four out of 38 patients $(11 \%)$ showed a possible recovery from coeliac disease. All four had already undergone gluten challenge earlier in childhood at the ages of 2 to 5 and they had been on a gluten free diet before this challenge for a minimum of nine years. All nine patients with late initial diagnosis undergoing their first challenge relapsed.

IgA class gliadin antibodies were measured in all the sera. In 17 patients $(59 \%)$ the gliadin antibodies rose to positive levels concomitant with reticulin antibodies, and in two cases eight to 11 months earlier. In four patients the gliadin antibody titre varied back and forth from a negative result to a positive one at the same time as the reticulin antibodies gave a negative result and in two patients $\operatorname{IgA}$ class gliadin antibodies remained negative during the challenge and at the time of mucosal relapse. In the four young adults fulfilling ESPGAN criteria with possible postpubertal mucosal recovery $\operatorname{IgA}$ class gliadin antibodies were throughout at negative levels in three and varied in one.

IgG class gliadin antibodies were at positive levels at the time of biopsy in 18 of the 23 cases with mucosal relapse. In four of these IgG class gliadin antibodies were positive before reticulin antibodies. The titres varied in two during the challenge, and four adolescents and young adults with mucosal relapse showed no IgG class gliadin antibodies. In the four cases with normal mucosa at two years of 
gluten challenge IgG class gliadin antibodies were not at positive levels throughout in two and were positive once in one and twice in another, but were not found to be positive later.

\section{Discussion}

To our surprise not all the patients showed permanence of the mucosal reaction to gluten. Four $(11 \%)$ patients, three girls and one boy, still had a normal mucosa after two years on a normal gluten containing diet. They had all undergone a gluten challenge at a younger age and their mucosa had relapsed, so the ESPGAN criteria had been fulfilled. ${ }^{2}$ This finding can be explained in two ways. First, it is possible, as Schmitz et al have shown, ${ }^{5}$ that coeliac disease may disappear during adolescence in some patients, so that puberty could be a milestone in coeliac disease, changing to its currently familiar 'natural history'. Secondly, these patients could represent the extremity of normal biology, being only so called late relapsers who do not follow the 'two-year rule'. In fact, there is increasing evidence that the mucosa may deteriorate even after many years on a gluten containing diet, ${ }^{11}$ (I Polanco, $\mathrm{J}$ Larrauri. Abstract presented at International Coeliac Symposium, St Bartholomew's Hospital, London, 4-6 September, 1988) showing the diagnosis of transient gluten intolerance to be incorrect at least in these cases. Our four patients will be further followed up and it may of course turn out that the challenge is life long, meaning that the coeliac disease has healed. Without the present postpubertal gluten challenge study these patients would have continued unnecessarily on their gluten free diet.

Today it can be suggested that factors other than gluten ingestion are at least sometimes needed to induce mucosal damage in coeliac disease. An intriguing candidate trigger is adenovirus, as suggested by Kagnoff et al. ${ }^{12}{ }^{13}$ Such possibilities should be studied more extensively. The existence of external factors could offer explanations for the reported phenomenon of coeliac disease relapse over such a large range of time, ${ }^{11}{ }^{14}$ which has been confirmed in this study.

An interesting finding in the present study was the paucity of abdominal symptoms during gluten challenge. In most cases $(\mathbf{7 0 \%})$ the mucosa relapsed before any symptoms had occurred. Recently Kumar et al also observed that teenagers with coeliac disease not following a strict gluten free diet, and with mucosal abnormality, were clinically asymptomatic. ${ }^{15}$ It can be assumed that many of the young adults in the present study would probably not have developed any abdominal symptoms irrespective of small, flat intestinal mucosa. Likewise in many studies dealing with adult coeliac disease it has been noticed that patients may have only mild or no abdominal symptoms, and they may not have signs of malabsorption. ${ }^{16}{ }^{17}$ This we also observed in a recent family study where $9 \%$ of first degree relatives of coeliac patients were found to have coeliac disease. ${ }^{18}$ We encouraged the adolescents and young adults with mucosal atrophy to observe a lifelong gluten free diet even if they did not experience any symptoms at the present moment. Without a diet disease entities with symptoms and signs not commonly connected with coeliac disease, ${ }^{19}$ or even serious complications such as malignancies, ${ }^{20}$ may later occur. Jejunal mucosa with villous atrophy may accumulate oxidated metabolites of xenobiotics, leading to an increased risk of cancer. ${ }^{21}$

Our hypothesis concerning reticulin antibodies proved correct. In all but one patient we needed only one biopsy during the challenge. IgA class reticulin antibodies were the indicator and were found to be positive within one to 24 months on a gluten containing diet. Histologically a clear relapse into coeliac disease was seen even if all patients did not show flat mucosa. One patient with no symptoms had a negative reticulin antibody titre $(<1: 50)$ and showed flat mucosa at the end of the study. His serum was retested and the titre was found to be $1: 10$. We now start testing at $1: 5$ and this has not increased non-specific reactions. ${ }^{7}$ In our family study we found positive IgA class reticulin antibody titres in $3 \%$ of the relatives with normal mucosa. ${ }^{18}$ The hypothesis also worked in the patient with selective IgA deficiency; she developed IgG class reticulin antibodies. Thus the reticulin antibody test seems to be suitable for prediction of mucosal relapse in coeliac disease. In other studies it has been reported that several biopsies were often needed to establish the diagnosis. ${ }^{14} 22$

In the present study gliadin antibodies and reticulin antibodies behaved differently. In six of the patients IgA class gliadin antibody titres were positive before the reticulin antibody test showed positivity and in four of these the gliadin antibody titres decreased every now and then to negative levels. This may reflect the amount of gluten ingested. In our experience the gliadin antibodies often appear earlier than tissue autoantibodies such as reticulin antibodies. Bearing in mind our working hypothesis we did not biopsy the patients at the time of first appearance of positive levels of gliadin antibodies and therefore on the basis of this study it cannot be said to what extent gliadin antibodies reflect small bowel mucosal damage in coeliac disease. When reticulin antibodies were present 
later and the mucosa showed villous atrophy, however, gliadin antibodies were also at positive levels in most cases.

Should routine gluten challenge be applied in coeliac disease? According to Schmerling and Franckx it would not seem justifiable, as only a few patients with coeliac disease will not relapse after an interruption of gluten free diet. ${ }^{4}$ If we take the development of permanent tooth enamel hypoplasia into consideration, gluten challenge should not be made before the age of 3 years. Gluten reintroduction of short duration is recommendable. The appropriate age for gluten challenge is over 7 years, when all the crowns of permanent teeth have developed. ${ }^{23}$ In our gastroenterology unit we use gluten challenge at the age of 6 to 7 in children with a very early onset. of coeliac disease or if there has been any doubt as to the accuracy of the primary diagnosis. Otherwise we have felt safe with our diagnoses based on mucosal histology and the disappearance of symptoms together with reticulin and gliadin antibodies during dietary treatment. It should be stressed that over $60 \%$ of our primary diagnoses are today made at school age and only $10 \%$ before the age of 2 years. On the other hand, when the results of the present study are considered together with the findings of Schmitz et $a l^{5}$ routine postpubertal gluten challenge should be taken into consideration. More prospective studies are needed to ascertain the nature of coeliac disease.

This study was supported by the Emil Aaltonen Foundation, Finland.

\section{References}

${ }^{1}$ Meeuwisse GW. Round-table discussion. Diagnostic criteria in coeliac disease. Acta Paediatr Scand 1970;59:461-3.

2 McNeish AS, Harms HK, Rey J, Shmerling DH, Visakorpi JK, Walker-Smith JA. The diagnosis of coeliac disease. Arch Dis Child 1979;54:783-6.

${ }^{3}$ Mäki M, Kallonen K, Lähdeaho M-L, Visakorpi JK. Changing pattern of childhood coeliac disease in Finland. Acta Paediatr Scand 1988;77:408-12.

${ }^{4}$ Shmerling DH, Franckx J. Childhood celiac disease: a longterm analysis of relapses in 91 patients. J Pediatr Gastroenterol Nutr 1986;5:565-9.

5 Schmitz J, Arnaud-Battandier, Jos J, Rey J. Long-term followup of childhood coeliac disease. Is there a natural recovery? Pediatr Res 1984;18:1054.
${ }^{6}$ Mäki M, Hällström O, Vesikari T, Visakorpi JK. Evaluation of a serum IgA-class reticulin antibody test for the detection of childhood celiac disease. J Pediatr 1984;105:901-5.

7 Hällström O. Comparison of IgA-class reticulin and endomysium antibodies in coeliac disease and dermatitis herpetiformis. Gut 1989 (in press).

${ }^{8}$ Rizzetto M, Doniach D. Types of 'reticulin' antibodies detected in human sera by immunofluorescence. J Clin Pathol 1973;26:841-51.

9 Vainio E, Kalimo K, Reunala T, Viander M, Palosuo T. Circulating IgA- and IgG-class antigliadin antibodies in dermatitis herpetiformis detected by enzyme-linked immunosorbent assay. Arch Dermatol Res 1983;275:15-8.

10 Savilahti E, Viander M, Perkkiö M, Vainio E, Kalimo K, Reunala T. IgA gliadin antibodies: a marker of mucosal damage in childhood coeliac disease. Lancet 1983;i:320-2.

$"$ Kuitunen P, Savilahti E, Verkasalo M. Late mucosal relapse in a boy with coeliac disease and cow's milk allergy. Acta Paediatr Scand 1986;75:340-2.

12 Kagnoff MF, Austin RK, Hubert JJ, Bernardin JE, Casarda DD. Possible role for a human adenovirus in the pathogenesis of celiac disease. J Exp Med 1984;160:1544-57.

${ }^{13}$ Kagnoff MF, Paterson YJ, Kumar PJ, et al. Evidence for the role of a human intestinal adenovirus in the pathogenesis of coeliac disease. Gut 1987;28:995-1001.

14 Kumar PJ, O'Donoghue DP, Stenson K, Dawson AM. Reintroduction of gluten in adults and children with treated coeliac disease. Gut 1979;20:743-9.

15 Kumar PJ, Walker-Smith J, Milla P, Harris G, Colyer J, Halliday R. The teenage coeliac: follow up study of 102 patients. Arch Dis Child 1988;63:916-20.

${ }^{16}$ Swinson CM, Levi AJ. Is coeliac disease underdiagnosed? $\mathrm{Br}$ Med J 1980;281:1258-60.

17 Logan RFA, Tucker G, Rifkind EA, Heading RC, Ferguson A. Changes in clinical features of coeliac disease in adults in Edinburgh and the Lothians 1960-79. Br Med J 1983;286:95-7.

18 Auricchio S, Mazzacca G, Tosi R, Visakorpi J, Mäki M, Polanco I. Coeliac disease as a familial condition: Identification of asymptomatic coeliac patients within family groups. Gastroenterology International 1988;1:25-31.

19 Mulder CJJ, Tytgat GNJ. Coeliac disease and related disorders. Neth J Med 1987;31:286-99.

${ }^{20}$ Swinson CM, Slavin G, Coles EC, Booth CC. Coeliac disease and malignancy. Lancet 1983;i:111-5.

21 Ståhlberg M-R, Hietanen E, Mäki M. Mucosal biotransformation rates in the small intestine of children. Gut 1988;29:1058-63.

22 Packer SM, Charlton V, Keeling JW, et al. Gluten challenge in treated coeliac disease. Arch Dis Child 1978;53:449-55.

23 Aine L. Dental enamel defects and dental maturity in children and adolescents with coeliac disease. Proceedings of the Finnish Dental Society 1986;82(suppl 3):1-71.

Correspondence to $\mathrm{Dr} \mathrm{M}$ Mäki, Department of Paediatrics, University Hospital of Tampere, 33520 Tampere, Finland.

Accepted 3 July 1989 